\title{
The Current Employment Situation of Private College Graduates under Economic Downward Pressure and Its Countermeasures
}

\author{
Bayi Guan \\ Yantai Nanshan University \\ Yantai Shandong, China 265713
}

\author{
Zhanli Shang \\ Yantai Nanshan University \\ Yantai Shandong, China 265713
}

\author{
Hongwei Zhao \\ Nanshan Finance Company Ltd. \\ Yantai, Shandong, China 265706
}

\begin{abstract}
The impact of the economic downward pressure renders private college students three big pressures in terms of employment, first is the pressure of large scale layoffs from enterprises, the second is the pressure of poor cultivation quality of graduates, and the third is the pressure of graduates' low comprehensive quality, which have caused the present situation of the graduates' difficult employment. In order to solve these problems, private colleges plan to relieve employment pressure by virtue of the following methods: strengthen the construction of teaching staff, carry out students' practical skills training, strictly control the entrance threshold, offer the employment and entrepreneurship courses, cultivate students' consciousness of entrepreneurship and innovation and set up the private colleges brand effect. And the governments at all levels should strengthen financial and policy support to private colleges, guide the graduates to be employed prior to choosing a job to cope with the employment difficulty under economic downward pressure.
\end{abstract}

Keywords-economic downward; private colleges; graduates; current situation; countermeasures

\section{INTRODUCTION}

Economic downward pressure has influenced enterprise's survival and development for a long term, and has certain impact on private college students' employment. Thereby, the private college graduates face the employment pressure of "three low". The first is low position requirements as there are a large number of layoffs, which causes the significant reduction of recruitment plans, increasing competitive pressure; the second is low cultivation quality of the graduates which leads to further question of private college education quality; the third is the graduates' low comprehensive quality, and these graduates tend to think themselves above business, but have poor professional skills which narrows their employment space.

\section{CURRENT EMPloyment Status OF PRIVATE COLLEGE GRADUATES}

The gap of employment rate between private colleges and national colleges already exists, and it is especially obvious under the impact of economic downward pressure. In summary, current employment status of private colleges is reflected in the following three aspects.

\section{A. Pressure of Enterprises' Large Scale Layoffs}

Under the impact of economic downward pressure, a large number of enterprises have losses or sharp downturn profits. And the consumers' consumption level has fallen dramatically, and many enterprises face the crisis of rising costs and personnel surplus. Many of the layoffs are experienced employees with strong competition for corresponding work, resulting in the employment pressure on private college graduates.

The enterprises' reduction of personnel is to remove the incompetent employees or those don't meet the enterprise's development strategy by virtue of economic downward pressure on the one hand; and on the other hand, to make room for salary and position and for introducing excellent talents with high salaries; and the third is to reduce the enterprise's operating costs, break the current dilemma. We know that the purpose of enterprise is to make profits, and shareholders pursue profit maximization. Manpower is the active factor of enterprise development, the first element of productive forces, and the biggest part of human resource cost consumption. The role of human in management reflects in two aspects of promotion and hindering. Positive factor is the acceleration effect of human capital in the busy market of both production and marketing, and negative factors is the profit reduction effect of human resources cost surplus under weak market background.

Under the economic downward pressure, the enterprise's large scale downsizing is for their own survival, and the direct 
impact on private college graduates is the increasing employment pressure, narrowing employment channels and strict employment standard.

\section{B. Low Cultivation Quality of Graduates}

Private higher education has three purposes, first of all, due to its nature of enterprise with little national funding, it will inevitably pursue profit maximization for survival and development; second, the goal of teaching and education of higher education itself; the third is the targeted higher education will undertake supplementation of social education, therefore it has a public welfare purposes.

The financial resources of private colleges mainly consists of shareholder investment and part of the tuition with little state funding and social donation, which has determined shareholders' degree of concern of investment return. Under such conditions, private colleges shall maintain necessary expenditure and achieve the goal of profit by recruiting sufficient students. Fund is the first guarantee for private colleges' development. It is difficult to introduce in talents and the offices cannot operate normally without funds. Under influences of many factors, some private colleges adopt improper practice: the first is false promises, namely to sign the employment agreement upon students' entrance into the school, to increase attraction for parents and students, while neglecting the cultivation of knowledge and skills and the exercise of comprehensive quality, and the students will also render themselves a disguised pressure reduction; the second is paying no attention to the quality of the students with low admission threshold, which cause pressure in teaching in the future, and students' learning ability is uneven; the third is that there is no special enrollment and employment team, throwing all the tasks of enrollment and employment to professional teachers, and make it an indicator for teacher' performance, resulting in instability of teaching staff, thus they cannot keep their mind on teaching and necessary research, and the teaching quality is reduced. If things go on like this, the center viewpoint of enrollment and employment will be form in the teachers' mind, they will only pay attention to enrollment and employment to improve their performance while paying insufficient attention to teaching quality, in the long term, the teaching quality and competitiveness of private colleges will drop sharply.

\section{Graduates' Low Comprehensive Quality}

The comprehensive quality of graduates mainly refers to the comprehensive cultivation of the graduates such as moral education, psychological education, ability education, intellectual education, aesthetic education and physical education. Graduates' six education ability depends on their level of basic skills in basic education stage, also depends on the cultivation and exercise in the higher education stage. Employers tend to conduct comprehensive examination on applicants' ability education, intellectual education, physical education and aesthetic education with moral education and psychological education as the first principle, and judge whether or not they meet the needs of enterprises' development. In terms of moral education, private colleges generally do better, and some colleges even require students to master the contents of "Di $\mathrm{Zi}$ Gui", to strengthen moral education from daily behaviors.

Private college graduates mainly lack the cultivation of ability education and intellectual education, of which the basic reason lies in private colleges' faculty structure and the purpose to run this school. Most of the private colleges have no stable teaching staff, and the faculty is mainly formed by secondment, temporary teachers and college graduates. Such faculty is not stable, often resulting in the drain of teachers and lack of sustainable development. The secondment, temporary teachers are mostly the college teachers closing retirement or have retired, whose physical condition is not stable, and personnel files are kept in the original unit. So they will work here if it is suitable, otherwise, they will leave, resulting in poor stability. For college graduates, from the day they start to work, affected by the negative private college culture and working environment, their energy is not on the teaching and scientific research, but worry about layoff and job-transfer, causing negative influence on the stability of faculty. Analyzing from the perspective of Maslow's hierarchy of needs, when people have solved physical problems, the next concern to be considered first is security needs, of course including the security and stability of work, and then the team belonging needs, respect needs and self-worth realization needs. If a teacher's job stability cannot be guaranteed, how can he (she) focus on his work and to cultivate students? All will be impossible! The idea of seeking a stable work will still exist in his (her) mind, increasing the employees' psychological pressure. If it goes on like this, it will inevitably lead to the instability of the faculty of private colleges with poor teaching quality. And the chain reaction of poor teaching quality is students' low comprehensive quality, losing competitiveness in employment. As the time goes on, it will cause the question from society on private colleges and discrimination from employers, which is not conducive to the sustainable development of private colleges. Such enterprise culture of private colleges has also become the main reason why many outstanding graduates and senior talent are unwilling to choose private colleges.

"Rome is not built in a day". Another important reason for graduates' low comprehensive quality is low admission threshold and poor quality of the students. While recruiting students, many private colleges try everything possible to recruit students, neglecting the entrance threshold limit totally and forgetting the two functions of "selecting talents" and "cultivating talents" of higher education, causing the bad impression and distort understanding of private colleges from various social sectors. They believe that the goal of private college education is for the sake of profit while neglecting quality and anybody can be admitted as long as they spend money. Students' cultural differences upon admission will certainly lead to the difference in professional acceptance ability, and the quality of graduates will be different, which results in employment pressure. 


\section{COUNTERMEASURES TO SOlve PRIVATE COLLEGE GRADUATES' EMPLOYMENT}

The countermeasures are constructed as below through analysis of the current employment status of private college graduates.

\section{A. Stabilize the Faculty and Strengthen Faculty Construction}

The instability of private college faculty will influence students' sustainable development and the teaching's continuity. The process of teaching is a process of interaction between teachers and students. It not only involves the teacher's teaching, but also the students' learning. Teachers should learn about the characteristics of each student and teach them according to their ability. Students should adapt to the pace of the teacher's teaching. As for some teachers who teach the certain courses very well, students will like them very much and generate important dependence. If this teacher leaves at this time due to other reasons, students' learning interest that has just been cultivated will be impact significantly, over time there will be weariness.

Schools should strengthen evaluation on teaching quality and scientific research, and take it as an important indicator of teacher's annual assessment, and remove the impact on faculty by the incompatible factor with recruitment and employment as the main evaluation indicator. Lead the teacher's energy and mind to be concentrated on teaching and scientific research to improve the teaching quality, and raise public awareness of private colleges at the same time. One of the most core indicators of colleges' comprehensive ranking is the scientific research ability, the quality and quantity of the published papers. Many colleges have offered special bonus to reward and encourage scientific research, so as to enhance the comprehensive strength.

\section{B. Intensify the Introduction of Double Professionally Titled Teachers and the Mixed Type Teachers}

In order to improve students' ability education and intellectual education, private colleges should intensify the introduction of double professionally titled teachers and mixed type teachers, to ensure the teachers' ability of practice and theory. The double professionally titled teachers are required to have real experience. The double professionally titled teachers or mixed type teachers shall not be judged only by qualification certificate. They shall not only have the certificates but also have the practice experience and education certificate, to maintain a strict standard for introduction of talents. Double professionally titled teachers refer to the part time teachers having rich theory and experience selected from the school, industries, enterprises and administrative personnel according to the arrangement of teaching theory and practice in the teaching process, to explain the advanced knowledge of science and technology, policies and regulations, application technology and so on; mixed type teachers refer to the school requires certain years of professional experience and skills in addition to the degree required while receiving full-time teachers. ${ }^{[1]}$ To be strict with the introduction of double professionally titled teachers and mixed type teacher is not only for the college's long-term development, but also for the students' cultivation quality.

\section{Strictly Control Admission Threshold}

Private colleges shall be strict with admission threshold in the recruitment process. For students of poor quality, they shall dare to say "no" in front of money, to ensure our recruitment quality and admission principle. As for the student need to be admitted by lowering the admission line there shall be targeted class and teaching plan, to consider the students' comprehensive quality and acceptance ability, and teach them according to their aptitude with differentiated instruction.

\section{Open up the Courses of Employment and Entrepreneurship}

According to the survey and interview of the graduates of some private colleges, many graduates don't understand the importance of the employment agreement and the online signing process. They think that employment is just the employer want to employ them and only need to sign a labor contract, seriously neglecting the importance of employment agreement and personnel files to them. They even mistakenly think that it is all right to put the files in school, which shows their lack of understanding of employment knowledge and the importance of archives management, having no idea to protect their own rights and interests. In terms of employment, they are easy to trap into of probation period as set by some employers. Upon the expiration of the probation period, the opposite just sign labor contract but not sign the employment agreement, and do not receive the graduates' personnel files and registered permanent residence, resulting in the graduates' indifference to employment agreement and personnel file. Private colleges shall open up the employment and entrepreneurship courses and strengthen the employment guidance to clarify business ideas, which is not only a responsibility toward the graduates, but also an important way to increase the college's reputation.

\section{E. Establish Private College Brand Effect}

Establish private college brand effect to enhance comprehensive competitiveness and change social cognition. The establishment of brand effect relies on the quality of teaching and research, faculty construction and the guarantee of economic strength, which have determined the private colleges' brand effect. Many foreign universities such as Harvard, Yale, Cambridge and Oxford are established relying on the solid teaching and scientific research quality, and shape their world famous brand effect by virtue of strong economic strength and talented faculty. Their successful experience will generate significant influence on the development of private colleges in China and their brand shaping with certain reference significance.

\section{F. Increase Government's Financial Support to Private Colleges}

The funds for private colleges' development mainly consist of shareholder investment and tuition, which is are lack of sustained development, and it is difficult to get large quantity of fiscal fund support. Governments at all levels must pay full attention to the healthy development of private colleges, and invest in the funds as much as possible, to reduce the fund pressure of private colleges' development and promote the 
development of local private higher education, which is also an important channel to promote local economic development. Under the condition of abundant funds for development, private colleges will inevitably reduce the pressure of teachers' administrative affairs, make them return from the market to go back to school, learning and scientific research. And the private colleges will develop into a bright future.

\section{G. Change the Employment Concept}

Offer career planning guidance to private college graduates, and help them establish the phased objectives in their life development. Under pressure of economic downward, the graduates shall treat employment and select job correctly. And solve the problem of employment firstly to ensure economic source and life source, and then accumulate experience and choose other job again.

\section{CONCLUSION}

Only by strengthening their own comprehensive strength, creating good brand effect, improving the professional ability of graduates and solving the employment pressure can the private colleges attract students, guarantee the teaching scale, and obtain fund support. To achieve this goal, private colleges should develop an effective development plan: first of all, in terms of scientific research, formulate effective incentive system for teaching and scientific research from perspective of long-term teaching and research quality; second, in terms of quality, build a high quality and stable teaching staff, ensure the quality of teaching and scientific research; third, in terms of employment guidance, carry out the cooperation between colleges and enterprises to improve the students' professional skills and ability to adapt to the position, and gain the funding support from enterprises. If these are done ready, we believe that the private higher education will have a bright tomorrow!

\section{REFERENCES}

[1] Guan Bayi, Lu Xianghua. Positioning Study of Continuing Education Development [J]. Journal of Higher Correspondence, 2008(5).

[2] Hu Bangyao. Vocational Education and Training of Australia--Investigation Report of Australia TAFE. [J]. Chinese Vocational and Technical Education, 2001(1)

[3] Zhang Yuhua, Qin Faying. Operational Mechanism of Australia Adult Vocational Education [J]. Continuing Education Research, 2004(2).

[4] Zhang Yongcheng. Entrepreneurship and Operation[M].Beijing: Jinghua Press, 2008 